\title{
«Umbrales» de la víctima en la narrativa peruana: representaciones, construcciones, discursos
}

\author{
«Thresholds» of the Victim in Peruvian Narrative: \\ Representations, Constructions, Discourses
}

\section{LUCERO DE VIVANCO}

${ }^{a}$ Universidad Alberto Hurtado.

Correo electrónico: lvivanco@uahurtado.cl

El presente artículo tiene como objetivo problematizar uno de los asuntos más controversiales respecto de las representaciones de la violencia y las construcciones de memoria: la categoría de víctima y el problema de la victimización. Se propone la noción de «umbral» para complejizar las concepciones de la víctima formuladas dentro del paradigma de los Derechos Humanos, pues es en ese marco en el que aparece la categoría de víctima como la entendemos hoy en día. El artículo toma como caso de estudio las narrativas de memoria en el Perú, pues el conflicto armado a partir del cual surgen estas narrativas ha dejado innumerables muestras de una victimización espinosa y multifactorial, evidenciando las limitaciones de los modelos rígidos dentro de los cuales suele entenderse esta categoría.

Palabras claves: víctima, umbral, violencia política, memoria, narrativa peruana.

This paper aims to problematize one of the most controversial issues regarding the representations of violence and the productions of memory: the category of the victim and the problem of victimization. The notion of "threshold" is proposed to understand in a more complex way the conceptions of the victim formulated within the Human Rights paradigm, because it is in that framework that the notion of victim appears as we understand it nowadays. The paper takes as a case study the memory narratives in Peru, since the armed conflict from which these narratives arise has left innumerable signs of a thorny and multifactorial victimization, evidencing the limitations of rigid models usually used to understand this category.

Key words: victim, threshold, political violence, memory, Peruvian narrative. 


\title{
1. INTRODUCCIÓN
}

\author{
Quien traspasa el umbral se somete a una trasformación. \\ El umbral como lugar de trasformación duele. \\ Le es inherente la negatividad del dolor. \\ Byung-Chul Han, La expulsión de lo distinto.
}

El presente artículo tiene como objetivo analizar un conjunto textos narrativos peruanos para interrogar uno de los asuntos más relevantes, pero también más complejos y controversiales respecto de las representaciones de la violencia en el Perú: la categoría de víctima y el problema de la victimización. Asimismo, este artículo tiene como objetivo introducir teóricamente la noción de «umbral», dado que esta noción permite no solo problematizar la categoría de víctima dentro de las narrativas de memoria, sino también discutir las conceptualizaciones en torno a dicha categoría formuladas dentro del paradigma de los derechos humanos (DDHH) o dentro de lo que Fassin (2012) ha llamado la "razón humanitaria”. El marco de esta reflexión es el conflicto armado entre el Partido Comunista del Perú Sendero Luminoso (SL) y el Estado peruano (1980-2000) y las construcciones de memoria surgidas a partir de dicho conflicto, el que ha sido el episodio de violencia más intenso, más extenso y más prolongado de la historia republicana, con una estimación cercana a las 70 mil víctimas fatales (CVR 2004: 433).

El paradigma humanitario dentro del cual aparece la víctima como la entendemos hoy en día, se va gestando tras los acontecimientos extremos de la Segunda Guerra Mundial - y de otras situaciones de guerra y violación sistemática de los DDHH en Latinoamérica y el mundo- ante la urgente necesidad de compensar los sufrimientos vividos en esos contextos. Frente a perspectivas criminalistas del derecho penal focalizadas en descubrir quién y cómo se cometió la acción delictual, relegando al sujeto sobre el cual se había cometido la acción a un segundo plano, la razón humanitaria convierte a la víctima en una figura central y protagónica (Fattah 2014). Así, este enfoque humanitario viene a impregnar la articulación total de respuestas — discursivas, políticas, judiciales, asistenciales - respecto de las violaciones masivas a los DDHH, sobre todo en aquellos casos en los que, por su masividad, tales violencias están por encima de lo que el funcionamiento regular de la justicia penal es capaz de absorber. Dentro de este paradigma, se constituyen, por ejemplo, las comisiones de verdad, quienes hacen de la víctima el eje central de su preocupación, para dignificarla y garantizarle verdad, justicia, reparación y garantías de no repetición. En este sentido, se puede entender la razón humanitaria como el fundamento del modelo operacional de los DDHH. Con el tiempo, una "nueva economía moral" (Fassin 2012) llega a hegemonizar los lenguajes con los que se nombran y representan, en términos éticos más que políticos, los distintos ámbitos de la realidad. Así, los efectos de la violencia se formulan bajo codificaciones de sufrimiento más que de desigualdad, de trauma más que de abuso, de compasión más que de justicia; y los conflictos y las guerras comienzan a escribirse 
en términos de víctimas y perpetradores, lejos de la estructura vencidos/vencedores y de las terminologías y modelos propuestos por la tradicional épica militar (el fusilado, el lisiado de guerra, el caído en combate, el héroe).

El conflicto armado peruano - y sus narrativas de memoria- ha dejado innumerables muestras de una victimización espinosa y multifactorial, evidenciando las limitaciones del modelo humanitario para comprender la realidad de las víctimas de esta guerra fratricida y sus representaciones. La noción de «umbral» propuesta resulta, entonces, un concepto articulador, que permite complejizar las aproximaciones a la categoría de víctima. La utilización de esta noción se justifica al extraer de ella tres ideas fundamentales. En primer lugar, "umbral» como lugar de tránsito y pasaje, es decir, de conexión y movilidad entre dos espacios u órdenes liminares. A partir de esta acepción, podrán pensarse las eventuales continuidades, transmutaciones o transformaciones entre dichos espacios $\mathrm{u}$ órdenes y, para el caso que nos ocupa, entre la figura de la víctima y la del perpetrador. En segundo lugar, «umbral» como frontera divisoria entre posiciones contiguas pero opuestas - el adentro y el afuera en el origen del concepto-, aplicable en este caso a dicotomías tales como violencia/política, nosotros/enemigos, pureza/perversidad, persona/animal, vida/muerte, cuerpo/desaparecido, memoria/silenciamiento, escritura/visualidad. En tercer lugar, «umbral» como límite —mínimo, máximo— de la percepción, la sensibilidad, el dolor, el entendimiento, la comprensión, la memoria, el tiempo, la justicia, el lenguaje, el silencio, la vida; lindes todos estos involucrados en la experiencia victimal.

El argumento central que se presenta en este artículo es que la categoría de víctima, analizada desde la noción de umbral tal y como aquí se define, se despliega de manera más compleja, es decir, dentro de espectros de significación y acción que rompen con definiciones polarizadas, naturalizadas o complacientes; tanto si se considera el grado de participación de la víctima en los actos de violencia que la involucran y su vulnerabilidad, como el discurso testimonial que la constituye y visibiliza como tal.

En concreto, propongo la introducción de tres umbrales, a partir de tres aproximaciones o criterios de clasificación respecto tanto de la narratología (enunciado y enunciación) como de la victimología. ${ }^{1}$ Primero, desde una aproximación representacional, propongo pensar a la víctima dentro del umbral de la pureza y la perversidad, a partir del criterio de su participación en los actos de violencia que la victimizan. Segundo, también desde una aproximación representacional, propongo pensar a la víctima dentro del umbral de lo esencial humano y lo contingente, a partir del criterio de la vulnerabilidad con la que se caracteriza al sujeto victimal. Tercero, desde una aproximación ya no representacional (víctima como sujeto del enunciado) sino de la (víctima como sujeto de la) enunciación, propongo pensar a la víctima dentro del umbral del lenguaje y el mutismo, a partir del criterio de producción discursiva o testimonial mediante la cual ella se constituye y visibiliza como tal.

\footnotetext{
${ }^{1}$ Para victimología ver: Fattah 2014; Giner 2011; Núńez de Arco 2010.
} 


\section{La victimización en el Perú}

Algunas de las conclusiones de la Comisión de la Verdad y Reconciliación (CVR 2004: 433-434) del Perú respecto de las víctimas ayudan a comprender la relevancia del problema y su complejidad. Ellas enfatizan que la violencia reprodujo las brechas socioeconómicas del Perú y ahondó las desigualdades de índole étnico-cultural, constatándose una relación directa entre, de un lado, situación de pobreza, exclusión social, lengua materna indígena, residencia rural, o menor grado de escolaridad y, de otro lado, probabilidad de ser víctima de la violencia. Por lo tanto, a diferencia, por ejemplo, de lo sucedido en las dictaduras del Cono Sur, en Perú la víctima no solo se vio afectada por cuestiones de violencia política derivada directamente del enfrentamiento armado entre los actores, sino que estuvo predeterminada a serlo por razones de violencia sistémica de larga duración.

Siguiendo el modelo humanitario, la CVR tuvo un enfoque centrado en la víctima para levantar esa categoría en términos jurídicos de cara a la justicia transicional, pero también para sensibilizar y crear una comunidad empática con quienes sufrieron las consecuencias directas de la violencia. En este sentido, buena parte del énfasis estuvo puesto en caracterizar a las víctimas en función de su vulnerabilidad socioeconómica y étnicocultural, y en términos de su inocencia, cuya distinción con el perpetrador se dejaba ver de manera directa y transparente. De este modo, la víctima se entendió como una víctima pura, inocente, pasiva, atrapada entre "dos fuegos" (Sendero Luminoso y Fuerzas Armadas). El "Registro Único de Víctimas" elaborado por el Consejo de Reparaciones del Ministerio de Justicia y DDHH (s. f.) confirma esta demarcación, en tanto que reconoce la condición de víctima a "las personas [...] que sufrieron vulneración de sus DDHH" (párrafo 4), pero señala expresamente que "no se consideran víctimas [...] a los miembros de las organizaciones subversivas" (párrafo 5). Se entiende que, además de la decisión política, no considerar a subversivos como víctimas tiene que ver con que, bajo ninguna circunstancia (incluso aunque hayan sufrido violación a los DDHH) hubo en ellos "inocencia" o "pasividad". Siguiendo esta línea, las reflexiones sobre esta categoría, fundamentalmente gatilladas por la pregunta de quién puede ser considerada/o víctima, han sido abordadas sin necesariamente cuestionar el principio "básico" que distingue a la víctima del perpetrador.

Por otro lado, el problema de la víctima y la victimización en las narrativas de memoria es complejo en varios sentidos. Antes que nada, y de manera general, porque el significado de víctima en sí mismo es dinámico e inestable, ha variado a lo largo de la historia y sigue haciéndolo de acuerdo a factores contextuales y dependiendo de la perspectiva desde la cual se aborde y enuncie. ${ }^{2}$ Pero también por la particularidad de la

\footnotetext{
${ }^{2}$ Baste señalar, como ejemplo, el desplazamiento semántico del término desde su sentido etimológico hasta su sentido político actual. Etimológicamente la palabra "víctima" proviene del latín victima, que refería a la "persona o animal destinado a un sacrificio religioso" (Corominas 1961). De acuerdo a este sentido sacrificial, víctima era "un sujeto del orden de lo extraordinario, de la epopeya: es el sacrificado por todos (mártir), es el muerto para todos (héroe), es el expulsado para preservarnos a todos (chivo expiatorio)" (Gatti 2017: 39). Sin embargo, este sentido sagrado se ha ido perdiendo en la modernidad y la víctima ya no se concibe desde
} 
víctima peruana, cuya victimización — como reveló la CVR—excede los marcos históricos y políticos del conflicto armado interno y penetra en los contextos de "paz". A esto hay que sumar que se han construido en el Perú narrativas heroicas sobre la victimización que simplifican el problema, en tanto que polarizan el binomio víctima/victimario, sin reconocer las zonas de entrelazamiento. Al respecto, Hibbett (2019) ha señalado que las narrativas heroicas son las "preferidas" por los actores directos (SL, instituciones militares, políticos responsables durante el periodo), porque ninguno de ellos "tiene entre sus intereses políticos el reconocimiento de las complicadas zonas grises del conflicto que desafían los marcos legales existentes" (151).

\section{UMbral de LA PUREZA Y LA PERVERSIDAD: PARTICIPACIÓN DE LA VÍCTIMA EN LOS ACTOS DE VIOLENCIA}

Uno de los principales criterios de clasificación de la víctima es el de su "participación o contribución victimal en el delito" que la victimiza (Varona 33): una víctima que no participa o no contribuye con su victimización es una víctima inocente. Como ya se adelantó, según el punto de vista de los $\mathrm{DDHH}$, este criterio establece una dicotomía excluyente entre la víctima "pura" y pasiva (la víctima no participante o inocente), y un victimario activo y perverso que causa el sufrimiento de la víctima.

Para el caso peruano, sin desconocer lo anterior y sin minimizar los efectos devastadores de la violencia infligida por Sendero Luminoso (responsable del $46 \%$ de las víctimas fatales) y por los agentes del Estado (30\% de las víctimas fatales), Theidon (2009) ha hecho notar la activa participación de los campesinos en la matanza, desmontando la idea de que ellos fueran víctimas inocentes atrapadas entre fuegos enemigos. Paradójicamente, señala Theidon, el campesinado - ya sea como fuerza de base de Sendero Luminoso o como integrante de los comités de autodefensa contrasubversiva - era parte del mismo grupo social que sufrió las mayores consecuencias de la violencia, dándole al conflicto una "naturaleza fratricida" (Theidon 2009: 20). En el campo de la crítica cultural, Denegri y Hibbett (2016) y Hibbett (2019) han señalado los peligros que acompañan el uso recurrente de la figura de la víctima pura, haciendo hincapié en la despolitización de las representaciones al homogenizar, bajo la percepción ética de la víctima, diferencias de tipo políticas, como origen étnico y clase social.

La idea de umbral permite — sin desconocer las responsabilidades individuales, colectivas o institucionales- cuestionar esta representación dicotómica y excluyente que desconoce los cruces y solapamientos entre ambos roles. De hecho, son las propias narrativas

el paradigma de la exterioridad: pierde definitivamente su sentido etimológico, su aura de excepcionalidad en tanto mártir o héroe, su "singularidad aristocrática", para convertirse en un sujeto común, ordinario. Incluso en tiempos recientes, desde su posición de vulnerabilidad, la víctima constituye un nuevo tipo subjetivo, central en la sociedad contemporánea. La posición de víctima es, en este sentido, una nueva forma de ejercer la ciudadanía (Gatti 2017). 
de memoria las que demandan esta mirada más aguda. En efecto, con la aparición en la escena literaria de dos textos escritos por actores cercanos al conflicto armado interno, la categoría de víctima tal y como se venía entendiendo empieza a ser cuestionada "desde adentro". El primero es Memorias de un soldado desconocido. Autobiografia y antropología de la violencia, de Lurgio Gavilán Sánchez (2012), que constituye — para los estudios de memoria— el primer llamado de atención respecto de la necesidad de considerar la categoría de víctima desde una perspectiva teórica que permita superar la insuficiencia de la dicotomía mencionada. Porque el texto es el relato de una experiencia de vida cuyo autor y protagonista fue sucesivamente nińo-soldado de Sendero Luminoso (quechua hablante y analfabeto), miembro de las filas del Ejército que combatió a dicho grupo subversivo y, posteriormente, novicio franciscano, las tres posiciones durante el desarrollo del conflicto armado. Finalmente, cerca de veinte años después de haber dejado la zona de guerra, Gavilán, convertido en antropólogo, entrega el testimonio de una vida cuyas afiliaciones e identidades transitan por los distintos grupos involucrados en la violencia, ya sean estos grupos combatientes directos (Sendero Luminoso, Ejército) u observadores y generadores de conocimiento y opinión (Iglesia, Universidad). Se trata, pues, de un sujeto de enunciación que aglutina en una sola voz las posiciones de víctima, victimario, testigo y memorialista; que se representa a sí mismo en múltiples roles contrapuestos, y cuya mera existencia desestabiliza los imaginarios que oponen tajantemente a la víctima pura del perpetrador. La dicotomía víctima/perpetrador no alcanza para comprender esta vida real (ni su representación), más compleja e intrincada que la explicación que dicha dicotomía autoriza.

Porque pasar de la infancia campesina a Sendero Luminoso, de Sendero Luminoso al ejército, y del ejército al convento, todo durante el conflicto armado interno, es también una forma de moverse al interior de este umbral — defino por la participación en la guerra - que abarca distintos grados de victimización y perpetración. El texto evidencia distintas maneras en las que el protagonista circula entre los roles que asume y sus traslapes, intentando darle coherencia a una vida marcada por identidades y posiciones contradictorias. Una de ellas es haciendo una representación libre de juicios morales sobre las experiencias de la guerra, focalizándose más bien en lo cotidiano y en la humanización de los actores. Así, por ejemplo, el siguiente fragmento corresponde a una conversación entre Gavilán y la camarada Rosaura, durante el tiempo de su adscripción a Sendero Luminoso:

A veces ella pensaba en desertar: "Será en mayo", decía, "nos iremos para mi cumpleaños". Estas cosas se decían solo en secreto; pues apenas se enteraban los camaradas, en seguida fusilaban. Sí, pensábamos en abandonar el PCP. Es verdad que los cantos nos internalizaban que éramos de acero, pero éramos humanos, niños, campesinos gritando entre las rocas inertes sin que nadie escuchara. "Yo vine por mi hermano", le decía; "lo sé", me contestaba ella, "pero no solamente has venido por tu hermano, el PCP nos necesita, el Perú nos necesita” (97).

Incluso si el texto se focaliza en la propia posibilidad de pasar de un rol a otro, de una "institución" a otra, la representación de la situación muestra el tránsito fluido entre los 
extremos. Esto es notorio, por ejemplo, cuando, durante una ronda militar, el protagonista tiene un encuentro con religiosas misioneras:

Una vez, cuando subíamos la pendiente de Chincho a Viviana, la madre monja me habló de esta forma: “¿Usted puede ser sacerdote”! Solté una carcajada inocente, y dije: "No madre, yo tengo pecado grave y seguro Dios me bota a patadas". " ¡No, no!", me respondió, "Dios vino al mundo a buscar a los pecadores". Las palabras de la madre hasta me hicieron soñar que andaba con el sayal puesto, curando las heridas de las balas, dando de beber a los sedientos, reconciliando a los de SL con los militares. Pero, más que sueños, esa parecía ser la oportunidad que estaba buscando desde niño. Hacer algo por los que no tienen, por mis paisanos que tanto habíamos maltratado, robándoles y violando a sus mujeres (127).

Otra estrategia del texto es la de advertir el desborde de umbrales en tanto límites humanos - corporales y psíquicos - de resistenciay sobrevivencia, como posibles motivaciones para relativizar las diferencias entre los mencionados roles. Así, el dolor, el hambre, la muerte, la enfermedad o el frío aparecen en el texto frecuentemente para mostrar estas experiencias humanas - universales - más allá de las posiciones o del tipo de participación dentro del conflicto armado. Los siguientes fragmentos refieren a Gavilán en su etapa senderista:

Ese día no comimos nada, ni los días siguientes. Nuestros estómagos estaban vacíos, solo comíamos sal con nevada. Estábamos flacos. Los compañeros comenzaron a toser. Al sexto día dos de nuestros compañeros amanecieron muertos. Los mandos decían: "Estamos haciendo historia", pero ya no escuchábamos los demás discursos. Arrastraron a los muertos entre las rocas (92-93).

Siento que el tiempo se atraganta en mi vida y este recuerdo me duele y duele; siento en los brazos, en las piernas, en el corazón. Siento que el recuerdo se alimenta como las pulgas o los piojos blancos que se alimentaron de mi sangre cuando clandestino caminaba con fusil en mano, leyendo la biblia de Mao Tse Tung (164).

En esta última cita, llama la atención especialmente la expresión fragmentada del propio cuerpo (brazos, piernas, corazón, sangre); la noción de tiempo separada de la noción de vida (tiempo atragantado en la vida), la idea del recuerdo que vive como si fuera un parásito externo (recuerdo como pulga o piojo), y la disociación implícita en "leer" un libro cuando se es analfabeto. Todo esto en una combinación de desintegración, despersonalización, sentimiento de irrealidad, límites de la experiencia victimal sobrepasados por la coyuntura de la guerra, y que contribuyen a construir la imagen "victimizada" de una "perpetrador" (entendido como grupo-actor del conflicto armado, no en términos individuales). ${ }^{3}$

\footnotetext{
${ }^{3}$ El año 2019 Lurgio Gavilán Sánchez suma otro texto en el que vuelve a remecer la supuesta distinción de estos dos polos marcados por la participación en el conflicto armado interno y que, por lo tanto, debe ser leído
} 
El segundo texto que tempranamente pone en jaque la rigidez de la dicotomía víctima/perpetrador es Los rendidos. Sobre el don de perdonar, de José Carlos Agüero (2015). Agüero es hijo de padres combatientes de Sendero Luminoso, ejecutados extrajudicialmente por su militancia. Su madre, al recibir tres balazos por la espalada tras ser detenida por militares. Su padre, en lo que se conoce como la "masacre de los penales", que acabó con más de un centenar de detenidos amotinados, que ya se habían rendido. Desde un lugar de enunciación autobiográfico, ensayístico y testimonial, Los rendidos cuestiona varios de los sentidos comunes con los que se suele dar significado al periodo de violencia, como la culpa, la herencia y el perdón. Pero, específicamente para el problema de la victimización, Agüero hace colapsar la idea que se tenía de la víctima, al cuestionarla en al menos dos sentidos. Por un lado, poniendo en entredicho, él también, la supuesta distinción nítida entre las posiciones de víctima y victimario dentro del conflicto armado interno. Fundamentalmente, problematizó la exclusión mutua de estos roles al visibilizar al senderista que ha sufrido la violencia represiva —e ilegal - por parte de los agentes del Estado: tortura, muerte, secuestro, ajusticiamiento extrajudicial, desaparición forzada. Es decir, cuando el perpetrador "principal" (responsable del 54\% de los muertos o desaparecidos, según la CVR) sufre las mismas violaciones a los DDHH que las víctimas "inocentes" o "puras" o "pasivas". Esta situación victimal — la del terrorista torturado, violentado- no fue reconocida como tal en el Plan Integral de Reparaciones ${ }^{4}$ recomendado por la CVR, ni en las ONGs de asistencia a las víctimas, ni en los discursos políticos o sociales hegemónicos respecto de la memoria. Sobre estas víctimas, nos dice Agüero en Los rendidos, al consensuarse que no formen parte de las reparaciones, se negoció sobre un derecho humano fundamental que no debiera ser negociable dada su universalidad. Más aún, estos sujetos fueron alejados de la historia y expulsados incluso del lenguaje, como si se tratara de una pesadilla o una enfermedad: “¿en qué páramo sin nombre quedan estos sujetos? ¿En qué lugar sin nombre dentro de nuestro mundo de memorias y derechos? / Fantasmas que ni siquiera pueden ser víctimas, que son no-enunciables en el lenguaje convencional, semisujetos" (Agüero 2015: 104). En otras palabras, las propias definiciones formuladas dentro de las instituciones de DDHH en Perú no son suficientes para dar cuenta de este tipo de situaciones de victimización. Por ello, Agüero subraya la estrechez con la que están construidas las distintas identidades de la violencia —entre otras, el inocente y el culpable — y la necesidad de abordarlas con mayor profundidad en la discusión sobre la memoria. Pensar estas situaciones de victimización dentro del umbral de la pureza y la perversidad permite situar al sujeto considerando ambas posiciones, sin necesidad de fijarlo en alguno de ellas.

desde el umbral de la pureza y la perversidad: Carta al teniente Shogún. Desde el género epistolar, el autor escribe al militar que lo "rescató" de una muerte segura, cuando era niño soldado de Sendero Luminoso y fue interceptado por una patrulla militar. En ese enfrentamiento, Shogún decide no matar al niño senderista, como solía suceder dentro de la guerra sucia, razón por la cual recibe reconocimiento y gratitud por parte del autor. Gavilán construye en esta narración un nuevo actor del conflicto armado: el "militar compasivo", que desdibuja la idea de ese actor como un perpetrador de violaciones a los DDHH.

${ }^{4}$ http://www.ruv.gob.pe/ruv_victimas.html 
Por otro lado, Agüero también planteó en Los rendidos la necesidad de pensar a la víctima como un sujeto multidimensional y no confinado a dicha condición de víctima. En otras palabras, planteó la necesidad de recuperar la identidad integral y la agencia del sujeto victimal. Según esta crítica, que hace eco a un cuestionamiento más global al paradigma humanitario, se rechaza que la victimización sea algo que cope la identidad del sujeto, es decir, que el sujeto sea visto solo en función de su dolor, su carencia, su poca o nula capacidad de respuesta a la situación que lo violenta, o sus escasas competencias para reconstruirse posteriormente. El cuestionamiento desarma, entonces, una manera sustantiva de ver al sujeto victimal, sustantividad que dificulta su transición hacia otros roles no victimizados, que confunde "a la persona con su experiencia, o bien [tiende] a convertir la experiencia en una forma fosilizada de su identidad" (Beristain 18). Agüero propone reposicionar al sujeto en su agencia política, de enmarcar su historia dentro de las decisiones que el sujeto tomó respecto de la revolución emprendida; de que, como lo ha expresado Jelin, importe no solo lo que le hicieron sino también lo que él hizo (Jelin 2002: 15). Restablecer agencia en la víctima implica, por lo tanto, destacar "su voluntad, sus motivaciones, su perfil político" (Agüero 2015: 97); reintroducir su identidad de militante o el sentido en el que sus acciones fueron inscritas (Cardozo y Michalewicz 2014); de lo contrario, la víctima queda desperfilada tras un proceso de purificación que convierte al sujeto en un ser unidimensional, que pone de relieve únicamente el daño sufrido (Agüero 2015: 96).

Problematizar la categoría de víctima dentro del umbral de la pureza y la perversidad, hace que aparezca una víctima impura, sucia, que en el transcurso de su propia trayectoria - por diversas motivaciones, desde las ideológicas a las de mera sobrevivencia- ha oscilado dentro del espectro marcado por ambos extremos, escapando de la clasificación polarizada de víctima y perpetrador. La víctima recupera así sus mudanzas, sus contingencias, sus resistencias, su agencia y su identidad integral. Bajo este umbral, víctimas y perpetradores existen vinculándose a través de fronteras permeables, conviviendo en una "zona gris", indescifrable, como testimonió Levi (1989), una zona en la que las fronteras entre el "nosotros" y el "enemigo" son confusas, múltiples, difusas, móviles.

\section{UMBRAL DE LO ESENCIAL HUMANO Y LO CONTINGENTE: VÍCTIMA Y VULNERABILIDAD}

De acuerdo a la victimología, "el riesgo y la vulnerabilidad" (Varona 33) es otro criterio clave en la clasificación victimal. Dentro del paradigma de los DDHH alimentado por una ética filosófica - se ha subrayado la vulnerabilidad de la víctima en términos esencialistas. Según esta, lo humano está definido por su dimensión vulnerable, sufriente, precaria, desposeída (Butler 2004, 2009; Reyes Mate 2009; Ricoeur 1990), por su "ontología carencial" (Alonso 2009); por su "Yo, [que] de pie a cabeza, hasta la médula de los huesos, es vulnerabilidad" (Levinas 1993: 123). La vulnerabilidad constituye el ser de lo humano, el ser de la comunidad humana (Butler 2004). Estas teorizaciones se desarrollan sobre la carencia y la negatividad: la condición humana dañada, violentada en su dignidad, 
devastada en su inocencia, despojada de su integridad. De este modo, la víctima emerge en el padecimiento de un sinnúmero de "figuras del mal", siempre mediante un acto provocado voluntariamente por otro sujeto: amenaza, coacción, asesinato, tortura, desaparición forzada, violencia en el lenguaje. Se trata de un "poder ejercido sobre una voluntad por una voluntad" (Ricoeur 1990: 233), para expropiarle su valor, arrebatarle su moral, despojarla de su sentido. Esta negación del sentido es el núcleo de lo que Alonso (2009) llama la "razón desposeída de la víctima", porque a diferencia del perpetrador que siempre tiene su "razón" para violentar, "no hay un universo simbólico [para la víctima] en el que su daño resulte comprensible" (21). La víctima llega incluso a convertirse en el otro distinto (Ricoeur 2000) por la radicalidad de su vulnerabilidad y las secuelas de la violencia extrema sufrida: el "hundido" (Levi 1989), el "no-hombre" (Agamben 1999), el "ontológicamente carente" (Alonso 2009), el "que está más allá de los límites morales de la existencia” (Gatti 2017: 44).

Sin desconocer esta vulnerabilidad inherente al ser humano, quisiera volver a presentar el argumento, basado en los datos levantados por la CVR, de que lo específico de las víctimas en el Perú es el suplemento de un tipo de vulnerabilidad contextual, relacional, intersubjetiva, rastreable históricamente y sujeta a las estructuras sociales, y que es este tipo de vulnerabilidad multifactorial y contingente la que "promueve" o "justifica" el ejercicio de la violencia radical. Es decir, es la condición de desprecio y de no-reconocimiento del otro (su alteridad, su subalternidad; su condición de pauper, indígena, quechua hablante) lo que activa al poder y a los agentes que ejercen la violencia a cometer abusos extremos y a decidir respecto de las vidas "que cuentan" y hay que proteger frente a las que no (Mbembe 2006). A una víctima vulnerable en este sentido, se opone un perpetrador dispuesto a vulnerarla en grado máximo, psíquica, moral y corporalmente. ${ }^{5}$ La noción de umbral, entonces, permitirá hacer una necesaria problematización del peso que tiene la dimensión ontológica en este criterio, para evidenciar la condición subalterna de la víctima peruana como causal suplementaria de vulnerabilidad y violencia.

Persona (2017), de José Carlos Agüero, da cuenta de esta vulnerabilidad compleja. El texto conjuga — como Los rendidos - poesía, testimonio, autobiografía, ensayo y visualidad, para confrontar la buena consciencia de la memoria y la razón humanitaria; no para denostarla o renunciar a ella, sino para iluminar sus zonas grises, ciegas, complacientes, o derechamente re-victimizadoras. De este modo, Persona expone el legado de una guerra que está lejos de haber resuelto los problemas que la detonaron, y más lejos aún de haber asumido cabalmente sus consecuencias a nivel reparatorio. Alejándose radicalmente de esta idea de "recuperar" al sujeto victimal propuesta en Los rendidos, Persona propone: la violencia es constitutiva del orden, no es excepcional. El cuerpo no resiste su brutalidad. "[U]na enorme cantidad de nosotros no logramos conservarnos como sujetos un tiempo

\footnotetext{
${ }^{5}$ Las narrativas de memoria en el Perú no solo dan cuenta de los efectos deshumanizadores de la violencia extrema sufrida, sino también de la violencia extrema aplicada, es decir, del poder y los disciplinamientos extremos que generaron dicha deshumanización. De un lado, al violencia con la que el ejército intentó eliminar la subversión; de otro lado, las tácticas de enrolamiento y control de Sendero Luminoso y las consignas del terror que esta organización difundía.
} 
mínimo para fundar una historia o una experiencia que pueda ser transmitida o heredada. [...] Los sujetos se deshacen" (11). Y en su dilución, no dejan restos, solo huellas, sombras reconstruidas frágilmente por la imaginación de quienes van quedando.

Los distintos modos, ámbitos y grados en los que se manifiesta esta vulneración radical, acentuada por la condición subalterna de los sujetos victimizados, constituyen este texto. Para efectos de este artículo, pongo el foco en uno: ¿cómo se recuperan los cuerpos de los familiares asesinados, desaparecidos, ignorados, demolidos por la violencia sufrida?

Los familiares se ubican alrededor de un par de mesas largas. La habitación es pequeña, estrecha. Además de los familiares están los miembros del equipo de investigación forense del Ministerio Público. Sobre las mesas hay pequeńos cajones de madera. También, unas bolsas de papel. Los forenses las abren. Vierten su contenido sobre los cajones. Se observan pedacitos de hueso, grumos, astillas. Los familiares apenas se estremecen. Se acercan para mirar dentro de los cajones. Hay algo allí que es suyo. El forense, diligente pero práctico, como haría cualquier obrero que vacía el último concho de cemento de su saco, agita la bolsa, la golpea un poco para que caiga la tierra que se ha quedado atrapada en algún rincón. Como cuando coges la bolsa de arroz y la mueves para que nada se desperdicie (17).

El anterior es uno de los fragmentos en los que el texto muestra las limitaciones de los dispositivos de asistencia que, en el marco de la justicia transicional y la institucionalización de la memoria, se disponen para las víctimas y sus deudos. Aunque la situación narrada es violenta y revictimizadora en sí misma, al menos logra darle un marco asistencial a lo que también se vivió en total desprotección, dada la vulnerabilidad contingente de los sujetos victimizados. La experiencia de una mujer desplazada por la violencia desde Ayacucho hacia un barrio marginal de Lima así lo evidencia: "En su casa, en un barrio de Lima Norte, una señora guarda en una bolsa de plástico un trozo de falange. Es de su esposo. Lo sacó a escondidas de una fosa mal [h]echa, antes de venir a la capital huyendo de su pueblo" (19). En Persona, Agüero no solo nos introduce en el mundo de la tortura, el cadáver, el cuerpo desmembrado, la fosa común, sino también en los dilemas del NN, de la identidad y el reconocimiento, para exponer la dimensión tecnócrata y deshumanizada, ineficaz incluso, con el que se desarrollan estos procedimientos y el poco espacio de los sujetos vulnerados para contrarrestarlos. Me refiero a lo que Gatti ha llamado los procedimientos "en clave de re": reconocer, recuperar, recordar, reparar; una "banalidad del bien" para pensar la administración de lo humano en posición de desdicha, en tanto que se trata de "procedimientos que de tan extendidos, homogeneizados y normalizados, han dejado de pensarse" (181). Pero Agüero los piensa en profundidad para proponer, mediante sus representaciones, que el mundo de la norma, la técnica, el manual, dentro del cual estos procedimientos se despliegan puede generar consuelo, sí, pero también revictimización.

Por otro lado, este suplemento de vulnerabilidad es lo que está detrás de la profanación de los umbrales de lo humano más radicales: el que comunica pero distingue lo 
humano de lo animal; el que comunica pero distingue la vida de la muerte y, por lo tanto, el cuerpo del cadáver y, por lo tanto —una vez más—, las vidas memorables de las que son desechables del ámbito de la memoria. Leemos en Persona:

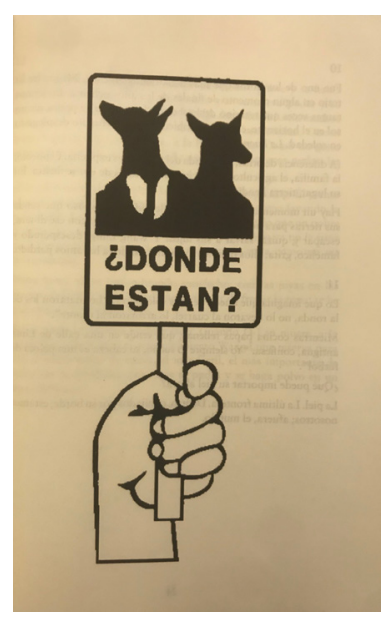

Para que la nueva oficina de búsqueda de personas desaparecidas los pueda hallar tendría que hacer un enorme catastro de animales:

gatos, gallinazos, zorros, moscas, alimañas. Y darles seguimiento.

Pero los trozos grandes de personas, los más sustanciosos, se los llevaron los perros salvajes de las quebradas. Ubicar a los perros: ¿abrirlos? Pero la mayoría han muerto. Las viejas de la asociación de víctimas, también. Entonces, ¿̨buscar a las crías?, ¿a las crías de las crías? (21).

Articulado con lo anterior, cabe la pregunta respecto de si, dado el suplemento de vulnerabilidad contingente, los contextos de paz son capaces de garantizar el cese de la victimización, una pregunta que se emparenta con la paradoja planteada por Agamben (1998) cuando propone que el estado de excepción del campo se convierte en norma de la modernidad. Para el caso peruano, del Pino (2013) ha señalado que los estudios del posconflicto

imponen una temporalidad definida a la violencia (1980-2000), con [lo] cual se ve ese tiempo coma uno excepcional y se normaliza la historia en la noción del pos. Sin embargo, ese esfuerzo por diferenciar el tiempo de la violencia puede llevar a encubrir y dejar de reconocer muchas prácticas y patrones de violencia que se reeditan en la actualidad contra poblaciones que son las mismas víctimas del conflicto armado (20-21).

El rebase de la victimización respecto del periodo del conflicto armado, por este suplemento de vulnerabilidad, tiene múltiples expresiones en el Perú. Un caso flagrante es el de la violencia ejercida contra la mujer durante la guerra, solo por el hecho de ser mujer. Algunas críticas (Denegri 2016) han sugerido ya la continuidad de la violencia de género en tiempos previos y posteriores a la guerra, vinculando la violencia sexual sufrida durante el conflicto armado con los feminicidios y violencias domésticas de las que son víctimas las mujeres en lo cotidiano como consecuencia del sistema patriarcal establecido. 
La sangre de la aurora (2013), de Claudia Salazar, aborda en su novela lo recién planteado. Tres mujeres son violadas en el contexto de la violencia. Si bien cada una de ellas tiene una participación diferente en el conflicto (guerrillera, periodista y campesina), su vulnerabilidad de género iguala sus experiencias de violación. De hecho, Salazar usa el mismo texto para intentar representar la escena de vejación contra la mujer. Únicamente cambian los apelativos con que los violadores se refieren a sus víctimas: Melanie es "blanquita vendepatria", "periodista anticomunista", "burguesa" (65-6); Marta es "terruca hijadeputa", "subversiva de mierda" (68); y Modesta, "serrana hijadeputa", "india piojosa" (69-70):

Era un bulto sobre el piso. Importaba poco el nombre que tuviera, lo que interesaba eran los dos huecos que tenía. Puro vacío para ser llenado. Ya sabían todo de ese bulto. En realidad no les importaba. Lo suficiente eran esas cuatro extremidades de las cuales podía ser sujetado, inmovilizado, detenido [...]. Daba lo mismo, ella era sólo un bulto. / Golpes en el rostro, en el abdomen, las piernas estiradas hasta el infinito [apelativo aqui]. Hacen fila para disfrutar su parte del espectáculo. Ningún orificio queda libre en esta danza sangrienta (65-69).

Ser mujer constituye así una vulnerabilidad que se impone sobre otras vulnerabilidades contingentes, como el origen social o cultural. Solo se "restablecen" las diferencias sociales entre ellas ante las distintas posibilidades u opciones que tienen para lidiar con las secuelas de la violación, como son la alterativa entre el aborto o la continuación del embarazo.

Problematizar la categoría de víctima dentro del umbral de lo esencial humano y lo contingente, hace que aparezca una víctima que ha recibido - y sigue recibiendo- una violencia acrecentada por sus condiciones socioculturales y de género, cuya victimización antecede y se mantiene tras el periodo de violencia. Bajo este umbral, identificamos contextos y condiciones específicas de victimización, que permitirían dar respuestas diseñadas para los contextos particulares, efectivas y apropiadas, no revictimizadoras. Pues, según las circunstancias y las vulnerabilidades, sin duda unas víctimas son más víctimas que otras, más allá del daño común a su humanidad.

\section{UMBRAL DEL LENGUAJE Y EL MUTISMO: LA VÍCTIMA Y SU CONSTRUCCIÓN DISCURSIVA}

Finalmente, la producción discursiva o testimonial mediante la cual la víctima da a conocer su dolor, se entiende como el criterio fundamental para que esta se constituya y visibilice como tal. Ya sea hecha de manera directa o mediada, la narrativa testimonial es imprescindible en esta operación. El testimonio es su relato vital, su argumento, su razón; es la herramienta principal para fundarse como sujeto victimal. Con el testimonio, la víctima sale al reencuentro de su dignidad y moviliza una operación institucionalizada de 
rescate. ${ }^{6}$ De acuerdo a lo anterior, se entiende que la víctima no ha estado siempre ahí, sino que es una "construcción de sentido [...] que exige, en muchos casos, un determinado relato que explique las relaciones sociales, precisamente, en clave de victimización" (Peris Blanes 2014: 295). Bajo este modelo, la CVR convocó a una "comunidad solidaria" (Achugar 1992) y recogió 17 mil testimonios, a partir de los cuales levantó la dimensión moral del conflicto armado y construyó el Informe final.

$\mathrm{El}$ asunto del testimonio es controversial dentro del paradigma de los DDHH, pues se ha cuestionado no solo la capacidad del lenguaje o la legitimidad del testigo para narrar la experiencia de horror (Levi 1989; Agamben 1999) —el mutismo sería su negatividad—, sino la asignación al testimonio de una veracidad moral incuestionable (se suspenden las legítimas sospechas que suelen aplicarse a otras narrativas o discursos), por tratarse precisamente de una narración de sufrimiento y horror (Giglioli 2014; Sarlo 2005). Volveré a ambos factores.

Sin desconocer estos problemas, desde una aproximación a la enunciación de los textos, propongo pensar a la víctima peruana dentro del umbral del lenguaje y el mutismo, para dar cabida a los distintos recursos comunicativos con los que se puede articular y transmitir un testimonio, más allá del sistema verbal (registros visuales, gráficos, fotográficos, cartográficos, orales, diglosia). La idea de umbral permitiría pensar la narrativa testimonial como una zona en la que se despliegan distintos lenguajes, incluidas las huellas del silencio y otros lenguajes no-letrados, y las hibridaciones e intermedialidades entre estos. Sostengo que la tendencia a diversificar e hibridar una variedad de lenguajes dentro del discurso testimonial no-judicial, responde no solo al esfuerzo por encontrar modos eficaces de simbolizar la experiencia de horror y construirse como víctima, sino que constituye también estrategias alternativas o de resistencia cultural a la hegemonía del modelo letrado de la élite. La idea anterior se justifica en tanto que lo letrado, como señaló Cornejo Polar (1994) para Perú, se ha configurado históricamente como instrumento de dominación y, consecuentemente, de victimización. Por lo tanto, las luchas por la memoria cristalizan también en las luchas por los lenguajes disponibles para construirla, extendiendo la dinámica hegemonía/subalternidad al campo de las representaciones.

Tal vez el mejor ejemplo de esto último sea el conjunto de testimonios recogidos por Edilberto Jiménez en Chungui, trazos de memoria (2005). Este autor, antropólogo ayacuchano y heredero de una tradición artesanal familiar en una de las zonas del Perú más deprimidas económicamente y también más afectadas por la violencia, colabora con la CVR en la toma de testimonios en la comunidad de Chungui. Jiménez empieza frecuentar Chungui desde 1996, buscando ganar la confianza de los comuneros, para investigar sobre la época de la violencia. Tanto en el documental Chungui: horror sin lágrimas... una historia peruana (Degregori 2009), como en el propio texto, Jiménez ha insistido en la resistencia

\footnotetext{
${ }^{6}$ Wieviorka (2006) se ha pronunciado respecto de esta construcción en términos de "la era del testigo", para aludir al surgimiento masivo, en la década de los 60 , de testimonios de sobrevivientes de los campos nazi tras la repercusión mediática que tuvo el juicio de Eichmann en Jerusalén.
} 

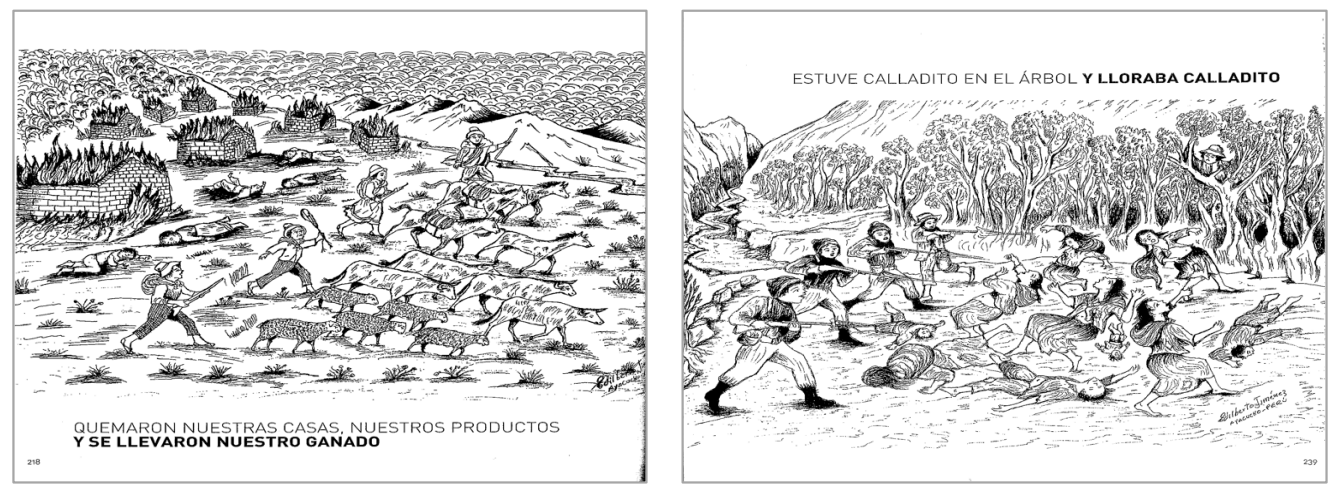

de los campesinos para dar sus testimonios: "en general los comuneros se negaban a hablar de eso. Era como si toda una población se hubiera puesto de acuerdo para no decir una sola palabra” (Degregori 2009: 12’25”), “era una cosa como prohibida hablar” (Jiménez 96), "existía un temor que impulsaba a no testimoniar y parecía que estaba absolutamente prohibido contar sobre la muerte" (Jiménez 98). Para "romper el miedo" (Jiménez 91), “para que también yo rompiera mi silencio” (Degregori 2009: 17’15”), Jiménez empieza a dibujar los relatos en vez de escribirlos o registrarlos en una grabadora. Esto cambia la disposición de la comunidad: abandonan el silencio y dan inicio a un proceso de etnografía colaborativa, en la que los "«informantes» no se convirtieron en coautores de sus textos sino de sus dibujos, que ilustran y expresan de otra forma el contenido de los testimonios, intensificando y ampliando la potencia del relato desde "lugares de visión» inexplorados" (Degregori 2005: 22).

A partir de la utilización de la imagen y de la resistencia a hablar / ruptura del silencio, propongo que, desde un gesto descolonizador (aún si este no fue planificado), este conjunto de testimonios invierte las jerarquías comunicacionales de la cultura letrada, en tanto que lo que llega al lector es una construcción intermedial (texto e imagen), en el que lo textual está supeditado a lo visual, pues es a partir de lo visual que los sobrevivientes se animan a romper el silencio, y es en lo visual donde los testigos depositan la confianza para afirmar el estatus de verdad (moral) de sus testimonios.

El silencio, como ha señalado del Pino (2017) para el caso peruano, no sería la imposibilidad —impuesta o propia — del lenguaje o del testigo para manifestarse, sino un lenguaje no-letrado más para hacerlo: "los silencios más que vacíos son 'voces' activas que informan y marcan la dinámica central en la producción de la memoria de la violencia en comunidades duramente afectadas por el conflicto armado" (44). La "imposibilidad" de simbolizar, por lo tanto, no tendría que ver exclusivamente con el trasfondo traumático de la historia, sino con la falta de condiciones para una recepción justa del testimonio. Las formas del silencio, tales como el rumor, el secreto, el recuerdo relegado al espacio íntimo 
(del Pino 2017), pero también los intersticios y elusiones en el discurso, son medidas de protección ahí donde se sospecha que no hay garantías de que se acepte la verdad moral del testimonio antes mencionada, cuando es una "víctima sucia" quien la entrega, o cuando es una "víctima vulnerada por su contingencia" la que construye su memoria. A través del repertorio de otros lenguajes no verbales, no textuales, incluido el silencio, se manifiestan versiones de la verdad y de la memoria epistémicamente desobedientes, parafraseando a Mignolo (2010), lejos del mutismo inhabilitante al que se refería Levi, pero lejos también de las tecnologías de registro hegemonizadas por la cultura letrada.

Por lo tanto, la idea de umbral permite pensar estas narrativas en sus procesos enunciativos, no solo para percibir su materialización dentro de un espectro de lenguajes posibles, sino para descubrir que ellas han invertido el "problema" del testimonio tal como ha sido descrito dentro del paradigma de los $\mathrm{DDHH}$, al cual me referí más arriba. Es decir, en contexto de desiguales relaciones de fuerza, el cuestionamiento sobre la veracidad del discurso testimonial de la víctima ya no se produce en la recepción crítica del mismo, sino que se ha desplazado a la instancia previa de enunciación, pues la desconfianza sobre las formas y los lenguajes del discurso testimonial $-\mathrm{y}$ la potencia de estos para transmitir su verdad - surge de las propias víctimas y lo modela.

\section{BALANCE: LA VÍCTIMA REPRESENTADA Y LA VÍCTIMA REAL}

$\mathrm{Al}$ releer una buena parte de las narrativas de la memoria dentro de la noción de umbral, especialmente aquellas que han sido construidas dentro del imaginario ético de los DDHH — permeadas, sin proponérselo necesariamente, deempatíayafectos-, la experiencia peruana da cuenta de cómo se construyen sujetos complejos, cuya identidad y agencia no han sido saturadas por su sufrimiento; indígenas que en su resistencia contrasubversiva han emprendido acciones armadas moralmente cuestionables, tensionados por el dilema "matar o morir"; militares que, en paralelo a prácticas institucionales de aniquilamiento, defendieron o rescataron a sujetos en estado grave de vulnerabilidad y deshumanización; terroristas que han sufrido violencia represiva por parte del Estado; victimización que trasciende los márgenes epocales del conflicto armado; sujetos victimizados y revictimizados por su condición subalterna; formas de testimoniar enmarcadas en prácticas culturales de resistencia. Nada de esto implica, como ha aclarado Etxeberria (2013) para el caso español, eliminar el "criterio moral de responsabilidad" para igualar "a quien sufrió la injusticia con quien sufrió de manera justa por su iniciativa de violencia" (39-40). Pero pensar la víctima dentro de la noción de umbral permite mirar formalmente estas zonas porosas, reconocerla en su "suciedad" humana, en las razones que explican la crueldad de la violencia, en las particularidades de sus testimoniar. No solo para cuestionar las conceptualizaciones de la víctima hechas en el marco del paradigma de los DDHH y la justicia transicional que la asiste, sino también para avanzar en una comprensión más profunda de las narrativas de memoria. 
Teorizar sobre la categoría de víctima, o complejizarla simbólicamente, no significa, de ningún modo, olvidar a la víctima real, de carne y hueso, y sus necesidades de reconocimiento, justicia y reparación. Por el contrario, se estima que estos legítimos derechos pueden satisfacerse más plenamente si el discurso sobre ella —y de ella — se acerca más a la diversidad de experiencias vividas, y si las memorias en construcción acogen esa diversidad, sin encasillar, sin estereotipar, sin prejuzgar. Los recientes movimientos como \#MeToo o \#NiUnaMenos — que tienen la virtud, en términos de política global, de haber expuesto masivamente una constante de violencia poco visibilizada hasta ahora- hacen eso: reconocen el abuso, pero no por eso entienden a la víctima bajo una única dimensión victimizada. Por el contrario, la empoderan. Complejizar la mirada sobre la víctima requiere considerar críticamente, además de las formulaciones hechas dentro del paradigma de los DDHH, al menos tres cosas: cuánto margen existe (si es que existe, si es que no hay coacción) para tomar la decisión de participar o no de las acciones violentas, cómo se distribuye social e históricamente la vulnerabilidad, y cuál es la aceptación que tienen los distintos recursos comunicativos de los subalternos para dar cuenta de la victimización sufrida.

La experiencia peruana y, en particular, sus narrativas de memoria, permiten observar que las trayectorias de las víctimas no son ni unidireccionales, ni homogéneas, ni estáticas. En este sentido, la noción de umbral propuesta, al focalizarse en los tránsitos, pasajes, conexiones, fronteras y límites entre posiciones opuestas y aparentemente excluyentes, da cabida, pero también responde a esta complejidad e inestabilidad, sin renunciar a la afirmación de la víctima en tanto persona violentada. Dicho de otro modo, a lo largo de este artículo, he intentado demostrar que la noción de umbral permite que se tengan en cuenta los extremos dentro de los cuales se despliega la víctima en su conceptualización y acción, pero para identificar su posición entre los extremos y no necesariamente para situarla en ellos.

Por último, Giglioli ha señalado que las "víctimas del futuro, las evitables, [son] las únicas de las que el presente tiene verdadera responsabilidad" (2014: 40). Estoy parcialmente de acuerdo: tanto desde el punto de vista ético como político, el presente también tiene responsabilidad sobre las víctimas del pasado. Ellas son nuestro presente. No obstante, sí concuerdo con la relevancia de incorporar en el horizonte del presente — político, ético y discursivo- a las "víctimas del futuro", no solo para dialogar de manera más cercana a sus experiencias de vida, sino para que ellas sean —efectivamente— "víctimas evitables"; para impedir o detener su victimización.

\section{Obras Citadas}

Achugar, Hugo. 1992. "Historias paralelas/historias ejemplares: la historia y la voz del otro". Revista de Crítica Literaria Latinoamericana, Año XVIII, 36: 49-71.

Agamben, Giorgio. 1998 [2016]. Homo sacer. El poder del soberano y la nuda vida. Valencia: Pre-Textos. 
. 1999 [2009]. Lo que queda de Auschwitz. El archivo y el testigo. Valencia: Pre-textos.

Agüero, José Carlos. 2015. Los rendidos. Sobre el don de perdonar. Lima: Instituto de Estudios Peruanos. 2017. Persona. Lima: Fondo de Cultura Económica.

Alonso, Martín. 2009. La razón desposeída de la víctima: la violencia en el País Vasco al hilo de Jean Améry. Bilbao: Bakeaz.

Beristain, Carlos. 2009 [2010]. Diálogos sobre la reparación: Qué reparar en los casos de violaciones a los derechos humanos. Costa Rica: Instituto Iberoamericano de Derechos Humanos.

Beverley, John. 1999 [2004]. Subalternidad y representación. Debates en teoría cultural. Madrid/Frankfurt: Iberoamericana Vervuert.

Butler, Judith. 2004 [2006]. Vida precaria: el poder del duelo y la violencia. Buenos Aires: Paidós. . 2009 [2010]. Marcos de guerra. Las vidas lloradas. Madrid: Paidós.

Cardozo, Gisela y Alejandro Michalewicz. 2014. "Ser o no ser 'víctimas". Página/12. 22 de enero de 2014. https://www.pagina12.com.ar/diario/elpais/1-238238-2014-01-22. html

Comisión de la Verdad y Reconciliación. 2004. Hatun willakuy. Versión abreviada del Informe Final de la Comisión de la Verdad y Reconciliación Perú. Lima: Defensoría del pueblo.

Consejo de Reparaciones. s. f. "Registro Único de Víctimas". Lima: Ministerio de Justicia y Derechos Humanos. http://www.ruv.gob.pe/registro.html (15 enero 2018).

Cornejo Polar, Antonio. 1994 [2003]. Escribir en el aire. Ensayo sobre la heterogeneidad socio-cultural en las literaturas andinas. Lima: Centro de Estudios Literarios Antonio Cornejo Polar.

Corominas, Joan. 1961 [1987]. Breve diccionario etimológico de la lengua castellana. Madrid: Gredos.

Degregori, Carlos Iván. 2005. "Edilberto Jiménez. Una temporada en el infierno". Edilberto Jiménez. Chungui. Violencia y trazos de memoria. Lima: Instituto de Estudios Peruanos, COMISEDH, DED, 2009. 18-35.

Degregori, Felipe. 2009. "Chungui: horror sin lágrimas... una historia peruana”. Lima: Buena Letra Producciones.

Del Pino, Ponciano. 2013. "Introducción: etnografías e historias de la violencia". Ponciano Del Pino y Caroline Yezer, eds. Las formas del recuerdo. Etnografias de la violencia politica en el Perú. Lima: Instituto de Estudios Peruanos: 9-24. . 2017. En nombre del gobierno. El Perú y Uchuraccay: un siglo de política campesina. Juliaca/Lima: Universidad Nacional de Juliaca / La siniestra ensayos.

Denegri, Francesca. 2016. "Cariño en tiempos de paz y guerra: lenguaje amoroso y violencia sexual en el Perú". Francesca Denegri y Alexandra Hibbett, eds. Dando cuenta. Estudios sobre el testimonio de la violencia politica en el Perú (1980-2000). Lima: Fondo editorial Pontificia Universidad Católica del Perú: 67-91. 
Denegri, Francesca y Alexandra Hibbett, eds. 2016. Dando cuenta. Estudios sobre el testimonio de la violencia política en el Perú (1980-2000). Lima: Fondo editorial Pontificia Universidad Católica del Perú.

Etxeberria, Javier. 2013. La construcción de la memoria social: el lugar de las víctimas. Santiago: Museo de la Memoria y los Derechos Humanos.

Fattah, Ezzat. 2014. "Victimología: Pasado, Presente y Futuro". Revista Electrónica de Ciencia Penal y Criminología 16.2: 1-33. http://criminet.ugr.es/recpc/16/recpc16-r2.pdf (10 marzo 2017).

Fassin, Didier. 2012. Humanitarian Reason. A Moral History of the Present. Berkeley: University of California Press.

Gatti, Gabriel, ed. 2017. Un mundo de víctimas. Barcelona: Anthropos.

Gavilán Sánchez, Lurgio. 2012. Memorias de un soldado desconocido. Autobiografía y antropología de la violencia. Lima: Instituto de Estudios Peruanos. . 2019. Carta al teniente Shogún. Lima: Debate.

Giglioli, Daniele. 2014 [2017]. Crítica de la víctima. Barcelona, Herder.

Giner, César. 2011. "Aproximación psicológica de la victimología". Revista Derecho y Criminologia: 25-54. http://repositorio.ucam.edu/handle/10952/573 (28 marzo 2017).

Guha, Ranajit. 1983. Elementary Aspects of Peasant Insurgency in Colonial India. Delhi: Oxford University Press.

Hibbett, Alexandra. 2019. "La problemática centralidad de la víctima en la memoria cultural peruana". Lucero de Vivanco y María Tere Johansson, eds. Pasados contemporáneos. Acercamientos interdisciplinarios a los derechos humanos y las memorias en Perú y América Latina. Madrid/Frankfurt: Iberoamericana Vervuert: 149-165.

Jelin, Elizabeth. 2002 [2012]. Los trabajos de la memoria. Lima: IEP Instituto de Estudios Peruanos.

Jiménez, Edilberto. 2005 [2009]. Chungui. Violencia y trazos de memoria. Lima: Instituto de Estudios Peruanos, Comisión de Derechos Humanos, Deutscher Entwicklungsdienst.

Levi, Primo. 1989 [2011]. Los hundidos y los salvados. Trilogía de Auschwitz. Barcelona: El Aleph Editores.

Levinas, Emmanuel. 1993 [2001]. Humanismo del otro hombre. México: Siglo veintiuno editores.

Mbembe, Achille. 2006 [2011]. Necropolitica. Santa Cruz de Tenerife: Melusina.

Mignolo, Walter. 2010. Desobediencia epistémica: retórica de la modernidad, lógica de la colonialidad y gramática de la descolonialidad. Buenos Aires: Ediciones del Signo.

Núnéz de Arco, Jorge. 2010. Victimología y violencia criminal. Un enfoque criminológico y psicológico. La Paz: Academia Boliviana de Ciencias Jurídico Penales.

Peris Blanes, Jaume. 2014. "Narrativas y estéticas de la víctima en la cultura contemporánea". Kamchatka 4: 293-324.

Reyes Mate, Manuel. 2009. "La ética de las víctimas como autoridad moral". Éxodo 100: 51-56. 
Ricoeur, Paul. 1990 [2006]. Sí mismo como otro. Madrid: Siglo XXI. . 2000 [2013]. La memoria, la historia, el olvido. Buenos Aires: FCE.

Salazar, Claudia. 2013. La sangre de la aurora. Lima: Animal de invierno.

Sarlo, Beatriz. 2005 [2013]. Tiempo pasado. Cultura de la memoria y giro subjetivo. Una discusión. Talca: Universidad de Talca.

Spivak, Gayatri Chakravorty. 1985 [2009]. ¿Pueden hablar los subalternos? Barcelona: Museu d'art Contemporani de Barcelona.

Theidon, Kimberley. 2009. Entre prójimos. El conflicto armado interno y la política de la reconciliación en el Perú. Lima: Instituto de Estudios Peruanos.

Varona Martínez, Gema et al. 2015. Victimología: un acercamiento a través de sus conceptos fundamentales como herramientas de comprensión e intervención. Open Course Ware (OCW). http://www.ehu.eus/documents/1736829/2010409/Manual+de+Victimol ogi\%CC\%81a+2015.pdf (11 junio 2020).

Wieviorka, Annette. 2006. The era of the witness. Ithaca: Cornell University. 